\title{
Individuals with HIV/AIDS ascribed several different meanings to their use of complementary therapy
}

Pawluch D, Cain R, Gillett J. Lay constructions of HIV and complementary therapy use. Soc Sci Med 2000 Jul;51:251-64.

\author{
QUESTION: What are the meanings that individuals with HIV/AIDS attach to their use \\ of complementary therapies (CTs)?
}

Design

Qualitative interpretive approach.

\section{Setting}

Southwestern Ontario, Canada.

\section{Participants}

66 people with HIV/AIDS (age range 21-66 y, 83\% men) who used CTs were identified through community contacts and organisations. 45 were white, 13 were of colour, and 8 were Aboriginal. Time since diagnosis ranged from 6 months to 9 years, and most participants were asymptomatic or had mild symptoms. 52 of the 55 men were homosexual.

\section{Methods}

20 semistructured interviews were completed in 1993-4 and 46 were completed in 1997-8. The interviews addressed such issues as factors in decisions to use CTs, belief systems about illness and HIV/AIDS, and judgments about efficacy. Collection and analysis of data used an inductive grounded approach.

\section{Main findings}

Respondents attached a broad range of meanings to CTs and fit them into ways of coping with AIDS in different ways. Most respondents saw CTs as part of a health maintenance strategy, the goals of which were to stay symptom free for as long as possible and to prolong life. They viewed HIV/AIDS as a chronic, manageable condition, and had a holistic understanding of health. CTs were described as anything that contributed to a sense of wellbeing and strengthened the body's natural capacity to fight illness (eg, reflexology, homeopathy, and prayer, as well as activities such as gardening and painting).Ethnocultural background was one factor that shaped individual thinking about CTs. For example, CT choices of Aboriginal respondents included sweat lodges and drumming. For those respondents who saw CTs more broadly as healing strategies, health had more to do with a sense of peace and personal fulfilment than seronegativity. Although they hoped for long term survival, philosophical concerns about the meaning of life and death outweighed concerns about physical health. Some viewed CT as an alternative to Western medicine. For those who rejected pharmacotherapy because of its side effects, CTs offered symptom relief and prophylaxis. Ironically, in contrast to the common assumption that people turn to unproven CTs after medical efforts are exhausted, some respondents saw Western medicine as their last resort. Furthermore, rather than being concerned about the safety of CTs, these respondents worried about the safety of Western medicine treatments, describing them as toxic and dangerous. Indeed, some who used medical treatment saw CT as a way of mitigating the side effects of drugs. Some respondents saw CT as a strategy for maximising quality of life, or as a coping strategy to manage anxiety and depression. Finally, some respondents viewed CT as political resistance, choosing CT to make a statement about the unresponsiveness and oppression of Western medicine and as a way of taking control of their health without having to rely completely on practitioners and treatments they did not trust. Their mistrust of Western medicine was informed by political analyses of homophobia, such as the slow response of Western medicine in the early stages of the HIV/AIDS epidemic, or racism, such as the historical maltreatment of Indigenous peoples.

\section{Conclusions}

Individuals with HIV/AIDS ascribed various meanings to their use of complementary therapy, which were neither mutually exclusive nor fixed. Meanings were linked to social characteristics (sexuality, ethnocultural background, and gender), beliefs, values, and experiences.

\section{COMMENTARY}

The findings of this qualitative study by Pawluch $e t$ al can assist nurses interested in understanding CT use among clients with HIV/AIDS. Evidence from the perspective of people with HIV/AIDS is presented through participants' personal theories about their own use of CT. The findings show that participants made thoughtful decisions about which healthcare practices would support current life priorities, and these decisions were contextually related to the person's life situation. For example, participants discussed 2 key reasons that a person with HIV/AIDS might reject Western medical treatment in favour of CT approaches. Firstly, this choice might represent an unwillingness to accept the reduction in quality of life that arises from the side effects of Western medicine. Alternatively, it could also represent a political statement in resistance to systems that have been oppressive for the client. The authors propose that being aware of and understanding personal theories about health care and practices will support health practitioners in working with clients and promoting health.

The findings show that healthcare decisions are based on multilevel, dynamic reasoning. Each participant's rationale for using CT included several of the 7 themes discussed. The complex and fluid nature of participants' healthcare decision making processes challenge some commonly held beliefs among health professionals (eg, CT use is based on reasoning that is either desperate and irrational or purposive and rational). Thus, the findings suggest that health professionals should maintain an ongoing and open conversation about their clients' perceived current life situations, and the considerations underlying their healthcare decisions.

Although these findings challenge some of the ideas held by health professionals about CT use by people with HIV/AIDS, the study sample represents a specific population subgroup-individuals who are HIV positive. It might be intriguing to consider whether similar patterns of treatment decision making occur in populations with other chronic illnesses. Clearly, additional research will yield useful insights into why clients make the decisions that they do and how nurses can best support them in their decisions.

Annette Schultz, RN, MN Doctoral Student, School of Nursing University of British Columbia, Vancouver, British Columbia, Canada 